\section{Projeto Bambuí: maneiras de pensar e agir de idosos hipertensos}

\author{
The Bambuí Health and Aging Study (BHAS): \\ ways of thinking and acting among \\ hypertensive older adults
}

\author{
1 Escola Nacional \\ de Saúde Pública, \\ Fundação Oswaldo Cruz, \\ Rio de Janeiro, Brasil. \\ 2 Núcleo de Estudos \\ em Saúde Pública \\ e Envelhecimento, \\ Centro de Pesquisas René \\ Rachou, Fundação Oswaldo \\ Cruz, Faculdade de \\ Medicina, Universidade \\ Federal de Minas Gerais, \\ Belo Horizonte, Brasil. \\ Correspondência \\ J. O. A. Firmo \\ Núcleo de Estudos \\ em Saúde Pública \\ e Envelhecimento, \\ Centro de Pesquisas \\ René Rachou, \\ Fundação Oswaldo Cruz. \\ Av. Augusto de Lima 1715, \\ Belo Horizonte, $M G$ \\ 30190-002, Brasil. \\ firmoj@cpqrr.fiocruz.br
}

\begin{abstract}
The ways older adults think about and react to high blood pressure were studied through an anthropological approach based on the Signs, Meanings, and Actions model 1. Twenty-six older adults ( $\geq 60$ years) participated in the study, randomly selected among hypertensive participants in the baseline of the Bambui cohort study. The central thrust of narratives showed a clear distinction between a "blood pressure problem" and high blood pressure. High blood pressure is perceived as caused mainly by family problems and is easily recognized by the identification of certain specific manifestations; blood pressure is only considered problematic when it increases, and this is the only moment in which interventions are considered necessary. Consequently, the importance of seeking treatment or following a medical prescription depends on the identification of rising blood pressure, either by the presence of specific symptoms or subjective conditions favoring the rise. Economic difficulties are also identified by seniors as factors hindering their ability to initiate or continue treatment of hypertension.
\end{abstract}

Aged; Hypertension; Anthropology
Josélia Oliveira Araújo Firmo 1,2

Maria Fernanda Lima-Costa 2

Elizabeth Uchôa 2

\section{Introdução}

O envelhecimento populacional constitui a mais importante mudança demográfica observada atualmente tanto em países desenvolvidos, quanto em países em desenvolvimento 2 . Uma importante conseqüência do envelhecimento da população é um significativo aumento da carga de doenças cardiovasculares, que constituem as causas mais freqüentes de óbito da população idosa nesses países, incluindo-se o Brasil 3,4,5. No Brasil, entre as doenças cardiovasculares, as doenças cerebrovasculares e as isquêmicas do coração são as causas mais freqüentes de morte 4 .

A hipertensão arterial é o principal fator de risco para doenças cerebrovasculares e doenças isquêmicas do coração, sendo a causa modificável mais importante para a morbidade e a mortalidade cardiovascular 6 . A prevalência da hipertensão aumenta com a idade e sua magnitude depende dos atributos biológicos/demográficos das populações, do estilo de vida predominante em cada uma delas, do ambiente físico e psicossocial, das características da organização dos serviços e das respectivas interações entre esses vários elementos 7. A hipertensão arterial exige tratamento contínuo e controle durante toda a vida e a baixa adesão ao seu tratamento representa um importante problema de saúde pública. Ainda é pequeno o número de hipertensos identificados e trata- 
dos adequadamente, e aproximadamente um quarto dos indivíduos hipertensos continua sem diagnóstico 8,9. Entre os diagnosticados, muitos desconhecem ser hipertensos e a maioria não busca tratamento. Cerca da metade dos que se tratam não apresentam a hipertensão arterial controlada 10.

Os estudos epidemiológicos identificam a distribuição da hipertensão arterial na população e os seus determinantes, fatores associados ao conhecimento da condição de hipertenso e/ou seu tratamento, entre outros. Os estudos antropológicos permitem conhecer em profundidade a percepção que as pessoas têm da hipertensão, como agem diante desta condição e quais fatores (econômicos, sociais e culturais) podem influenciar percepções e ações neste campo 11. Se por um lado os estudos epidemiológicos da hipertensão arterial no Brasil tem sido cada vez mais numerosos $4,12,13,14,15$, $16,17,18,19,20,21$, por outro lado, os estudos antropológicos ainda são raros 22,23.

A prevalência da hipertensão arterial é alta no Brasil, tanto em grandes centros urbanos, quanto no interior $14,15,16,18,20,24,25$. Na cidade de Bambuí, em Minas Gerais, Brasil, onde a prevalência da hipertensão arterial entre idosos é de $62 \%$, verificou-se uma alta prevalência de idosos que não sabiam ser hipertensos (23\%) e uma alta prevalência daqueles que, apesar de estarem sendo tratados, não apresentavam a hipertensão controlada (61\%) 12,13 . Estes estudos mostraram que os fatores modificáveis mais fortemente associados ao conhecimento da condição de hipertenso, bem como ao tratamento da hipertensão arterial, são o acesso e o uso de serviços de saúde. Entretanto, os resultados foram insuficientes para compreender quais são os fatores que influenciavam o comportamento dos idosos diante da hipertensão arterial e do seu tratamento, chamando a atenção para a necessidade de investigações mais profundas sobre formas de pensar e agir da população idosa bambuiense diante da hipertensão arterial. O presente trabalho tem por objetivo investigar as representações e ações associadas à hipertensão arterial nesta população.

\section{Modelo do sistema de Signos,} Significados e Ações

Em um estudo realizado com a população idosa ( $\geq 60$ anos) da cidade de Bambuí, verificouse que, apesar da alta prevalência da hipertensão arterial $(61,5 \%)$, foi baixa a percentagem daqueles que sabiam ser hipertensos $(76,6 \%)$. Além disso, apenas $62,9 \%$ dos que sabiam ser hipertensos relataram estar fazendo tratamento medicamentoso. Os fatores modificáveis mais fortemente associados ao conhecimento da condição de hipertenso 13 e ao tratamento da hipertensão arterial 12 estavam relacionados aos serviços de saúde, e mais especificamente ao acesso e uso dos serviços. Os resultados deste estudo apontam para a necessidade de melhor conhecimento do universo de crenças e normas de conduta que determinam as percepções e ações associadas à hipertensão.

No Brasil, são poucos os estudos que investigaram as percepções e os comportamentos da população em relação à hipertensão arterial. Dressler \& Santos 22 apresentaram um trabalho de revisão sobre as dimensões culturais e sociais da hipertensão no Brasil e Carvalho et al. 23 realizaram um estudo sobre concepções de hipertensão privilegiadas por pacientes idosos hipertensos que se tratavam no Centro de Reabilitação de Araraquara, São Paulo.

No presente estudo será empregado o modelo de análise dos sistemas de Signos, Significados e Ações ${ }^{1}$ com o objetivo de conhecer, de forma sistemática, como pensam e agem os idosos de Bambuí, diante da hipertensão arterial. Este modelo constitui um dos recentes desenvolvimentos da antropologia médica norteamericana, que tem sua origem na definição geertziana de cultura. Para Geertz 26, a cultura é um universo de símbolos e significados que permite a um grupo interpretar sua experiência e guiar suas ações. Esta definição foi fundamental para o desenvolvimento dos trabalhos do grupo de antropologia médica de Harvard. Este grupo adotou a perspectiva interpretativa de Geertz na abordagem de saúde e doença e estabeleceu uma diferenciação entre "doença experiência" (illness - experiência psicossocial da doença), e "doença processo" (disease - anormalidades dos processos biológicos e/ou psicológicos) 27,28 . Com base nisso surgiram outras contribuições: (1) o modelo explicativo (Explanatory Model - EM) desenvolvido por Kleinman 28 no qual a saúde e a doença são vistas como parte de um sistema cultural que fornece modelos para a identificação e a resolução de problemas nesse campo; (2) o modelo de análise de redes semânticas (Semantic Network Analysis) desenvolvido por Good 29 e Good \& Del Vecchio 30,31 que considera que elementos do contexto experiencial, social e cultural se articulam formando símbolos que intervêm na construção do significado dos episódios de doença 32 .

Segundo Uchôa 32 , a experiência da doença não pode ser considerada como um simples reflexo do processo patológico no sentido biomédico do termo; ela deve ser concebida como uma construção cultural que se expressa em 
“maneiras específicas de pensar e agir". Diversos estudos têm demonstrado que os diagnósticos profissionais e populares não são correspondentes 1,28,29,30,31. Enquanto a percepção dos profissionais (que quase sempre orienta programas de saúde) estaria associada aos conhecimentos biomédicos, a percepção da população (que orienta comportamentos) estaria relacionada a uma rede de símbolos articulando conceitos biomédicos e culturais 32,33,34.

Em continuidade com estes trabalhos, Corin et al. 1,35,36,37,38 desenvolveram o modelo de análise do sistema de Signos, Significados e Ações. Este modelo busca analisar representações e comportamentos associados a problemas de saúde específicos e em um contexto particular. Permite o acesso às lógicas conceituais privilegiadas por uma população específica para compreender e explicar uma determinada doença, assim como identificar os diferentes elementos do contexto que intervêm na construção de comportamentos concretamente adotados por esta população diante desta doença 34 .

\section{Metodologia}

\section{População estudada}

O estudo foi desenvolvido na cidade de Bambuí (cerca de 15 mil habitantes), situada no oeste do Estado de Minas Gerais. As principais atividades econômicas deste município são a agropecuária e o comércio. Como no resto do país, a relação urbano-rural inverteu-se: da população do município $84 \%$ residiam em zona rural em 1950; em 1991 este índice era 27\%. A composição etária da população também modificou, verificando-se seu envelhecimento progressivo: em 1960, somente $3,8 \%$ dos habitantes do município possuíam sessenta ou mais anos de idade; entre 1970, 1980 e 1991 esta proporção aumentou para 5,1, 7,3 e 9,3\%, respectivamente (maior, portanto, que a verificada em todo o Brasil em $1991=7,3 \%$ ). Entre 1990 e 1991, o Índice de Desenvolvimento Humano de Bambuí era igual a 0,7, a esperança de vida ao nascer era de 70,2 anos e $75 \%$ das mortes ocorriam entre pessoas com cinqüenta ou mais anos de idade. As principais causas de morte entre os habitantes deste município em 1996 foram acidente vascular cerebral, doença de Chagas e doença isquêmica do coração (taxas de mortalidade $=118,0 ; 61,4$ e 42,5 por $100 \mathrm{mil}$ habitantes, respectivamente). Maiores detalhes podem ser vistos em Lima-Costa et al. 4 .

Este estudo foi conduzido entre participantes da linha de base da coorte de Bambuí. A li- nha de base foi composta em 1997, contando com a participação de 1.606 idosos ( $\geq 60$ anos) que correspondiam a $92 \%$ de toda a população nesta faixa etária residente na cidade de Bambuí. Destes, 1.494 tiveram a sua pressão arterial aferida e 919 foram classificados como hipertensos. Foram classificados como hipertensos, aqueles que apresentavam a média de duas (segunda e terceira) entre três medidas de pressão arterial realizadas no mesmo dia $\geq 90 \mathrm{mmHg}$ (pressão sistólica) e $\geq 140 \mathrm{mmHg}$ (pressão diastólica), ou relataram estar fazendo uso de medicamento anti-hipertensivo 14,39. Para o presente trabalho foram sorteados trinta dos 919 idosos hipertensos participantes da coorte acima mencionada. Optou-se pela amostragem aleatória para garantir uma reprodução das características da população estudada.

\section{Coleta e análise de dados}

O modelo dos Signos, Significados e Ações, desenvolvido por Corin et al. 1,35,36,37,38 foi utilizado na coleta e análise dos dados, para permitir a sistematização dos elementos do contexto que participam da construção de maneiras típicas de pensar e agir diante da hipertensão 32,34 . Este modelo é baseado na reconstrução de casos concretos 34 .

Para reconstruir o universo de representações (maneiras de pensar) e comportamentos (maneiras de agir) associados à hipertensão arterial pelos idosos hipertensos residentes em Bambuí, foram realizadas entrevistas no domicílio do entrevistado. O tempo de duração das entrevistas variou entre vinte e trinta minutos, tendo sido iniciadas sempre com as perguntas: “O sr(a) já ouviu falar em hipertensão/pressão alta?", seguida de "O sr(a) tem hipertensão/pressão alta?". Caso o entrevistado dissesse que não era hipertenso, pedíamos para falar sobre alguém do seu conhecimento que fosse hipertenso. Por meio das entrevistas, procurou-se investigar o conhecimento do diagnóstico, a percepção das manifestações associadas à hipertensão, a idéia sobre a causa, a noção de gravidade, o tratamento medicamentoso (se é realizado ou não, se é prescrito ou não), facilidades/dificuldades para se fazer este tratamento (com relação a consultas médicas e/ou medicamentos e/ou outros), expectativa diante do tratamento, tratamentos alternativos, existência de cura, possíveis transtornos/repercussões, estratégias utilizadas pelos idosos para enfrentar a hipertensão.

As entrevistas foram gravadas e posteriormente transcritas. Após leituras atentas das mesmas, foram identificadas unidades signifi- 
cativas e criadas categorias analíticas. A codificação foi testada nas entrevistas e revisada para que todas as informações obtidas pudessem ser agrupadas fundamentando-se nestas categorias, com um mínimo possível de ambigüidade. Em seguida, foram identificadas as ocorrências de cada categoria analítica e feita extração de textos que correspondiam a uma ou mais categorias de informação para a análise de conteúdo. A partir daí, buscou-se a interação entre as distintas categorias.

\section{Resultados}

Maneiras de pensar e maneiras de agir frente à hipertensão arterial

Foram entrevistados 26 idosos, sendo $19 \mathrm{mu}$ lheres e 7 homens. Todos os entrevistados disseram já ter ouvido falar em hipertensão/pressão alta; quando interrogados se eram hipertensos ou tinham pressão alta, somente dois entrevistados negaram. Um deles afirmou que era seu irmão quem tinha problema de pressão: "Eu não tenho problema de pressão não, felizmente não. Tenho um irmão que tem" (homem 17) e o outro apenas disse que sua pressão é boa: "Eu não tenho (...) Minha pressão é boa" (homem 19).

A maioria daqueles que reconheceu ser hipertenso/ter problema de pressão alta, afirmou ter ficado sabendo por mero acaso, durante uma visita ao médico para pedir um atestado: "Foi por acaso. Eu fui ao médico (...) para ele me dar atestado, quando ele falou que a minha pressão estava alta" (mulher 26), ou para consultar-se por outro motivo: "Descobri por acaso porque fui no médico (...) então ele falou que minha pressão estava um pouco alta, mas eu não sinto assim nada não" (mulher 3). Um entrevistado explicou que ficou sabendo durante o Projeto Bambuí: "Eu não sabia que era hipertenso, com o andamento do Projeto Bambuí, eu descobri que era hipertenso e passei a cuidar" (homem 15). Somente quatro entrevistados afirmaram ter passado mal e quando procuraram o médico ficaram sabendo que o problema era a pressão; um deles relatou: "passei mal e falei 'não gente, mas agora está muito forte'. Fui ali no Posto. Eles falaram que a minha pressão estava alta" (mulher 6).

\section{$\underline{\text { Signos }}$}

A tonteira/zonzeira, bambeza/moleza, mal-estar/enjôo/vômito, dor de cabeça e alteração do sono foram freqüentemente associados pelos entrevistados à pressão alta. Um entrevistado explicou que ao sentir-se tonto, sabia logo que a pressão estava alta: "eu sinto o sinal, fico tonta" (mulher 16). Um outro disse que o médico confirmou esta associação entre tonteira e pressão alta: "quando a gente fica assim alterado, assim as veias do pescoço, eu sinto tonteira, muita tonteira na cabeça. Isso é por causa da pressão, eu sei porque eu vou consultar e às vezes interna (...)" (mulher 14). Outro entrevistado falou que sempre sabe quando sua pressão está alta e explicou: "mal estar, às vezes enjôo, dor de cabeça. Quando a pressão está muito alta, o estômago embrulha (...) estômago embrulhando, aquele mal estar, ou quando a gente alimenta que parece que a comida não fez bem, que a gente acha que está até precisando tomar um digestivo, sabe? Insônia, a gente perde muito o sono" (mulher 26). Para um outro, a dor de cabeça é o principal sinal de elevação da pressão: "Às vezes eu estou até tranqüila, não estou sabendo, mas ai eu sinto uma dor na nuca que mostra na hora que a pressão está subindo" (mulher 12).

Ansiedade, nervosismo, irritação, falta de paciência, agitação, desânimo e taquicardia também foram apontados como manifestações associadas à pressão alta. Dois entrevistados relataram saber que a pressão está alta quando sentem umas "ruindades". Um deles disse: " gente sente umas ruindades, umas coisas diferentes. Aí fui no médico, a pressão tava alta. A gente sente assim ansiosa, fica nervosa, agitada, sente que não está bem. (...) Eu sentia que o coração batia muito, dava aquela taquicardia, a pressão tava alta" (mulher 8) e outro confirmou: "Tem dia que (...) vem aquela ruindade nas minhas pernas, no meu corpo, parece que eu fico tremendo. (...) Eu acho que [a pressão] está alta quando dá esta ruindade" (mulher 24).

Como foi visto, a maioria dos entrevistados associa a elevação da sua pressão arterial à presença de problemas específicos. Quinze destes reconheceram, em determinados problemas, o sinal de que a pressão está alta ou vai subir. Outros três referiram-se à associação entre determinados problemas e a elevação da pressão, dizendo que alguém os teria informado disso. Um deles relatou: "diz que era pressão, os vizinhos fala, pessoas amigas da gente fala que é pressão" (mulher 13). Somente dois entrevistados disseram que não sentem nada e, portanto, não reconhecem qualquer associação entre sintomas específicos e hipertensão.

\section{Significados}

A maioria dos entrevistados diz que os problemas emocionais são a principal causa da pres- 
são alta. Um deles afirmou que "É emocional, contrariedade. (...) Com tanta amolação, aborrecimentos e alegrias também. (...) Tanto uma coisa quanto a outra, eu acho que é problema emocional. Faz a pressão subir, problema de pressão" (mulher 2). O nervosismo, as contrariedades (citados por sete entrevistados) e as preocupações (citadas por quatro entrevistados) são apontados como principais responsáveis pela elevação da pressão. As falas a seguir ilustram a influência do nervosismo e preocupação na elevação da pressão. Um entrevistado explicou: "fico nervoso e a pressão sobe, enrolo até a língua, fico conversando atrapalhado. (...) Quando eu fico nervoso suspende a pressão. (...) Toda vez que fico nervoso a pressão sobe" (homem 1), outro afirmou: "o tipo de vida que a gente leva. A vida moderna é muito agitada, preocupação demais. (...) A preocupação, passo horas sem dormir. (...) Isso altera a pressão. (...) A gente quando vai ficando mais maduro vai ficando mais temeroso, mais preocupado. (...) Isso tudo ajuda a atrapalhar a pressão da gente" (homem 15).

Vários entrevistados apontam a família (problemas familiares) como a fonte das contrariedades e preocupações que fazem a pressão subir. Um entrevistado relatou que fica contrariado sempre que tem problemas com a família e é neste momento em que a pressão sobe: "Quando eu tenho uma contrariedade, quando uma pessoa ou um filho fala qualquer coisa pra mim que me amola, ela [a pressão] faz só assim pra cima" (mulher 4). Outro disse que antes de se casar não tinha problema de pressão. As preocupações começaram após o casamento e por causa delas, surgiu o problema de pressão: "contrariedade, preocupação demais, aí ela começou a subir. (...) No meu caso, como já disse, é contrariedade, é problema de casa, né? Mesmo insatisfação por alguma coisa, com essas coisas" (mulher 12). Para um outro entrevistado, só o fato de ter família já é o bastante para ter preocupações e em conseqüência, problema de pressão: "Preocupação, eu acho que todo mundo tem, às vezes pode dar (...). Preocupa muito com a família. Às vezes pode dar pressão alta. (...) Preocupo com a família, com os filhos, sempre a gente preocupa muito" (homem 16). É interessante ressaltar que o nervosismo é considerado pelos entrevistados, tanto causa quanto sinal de que a pressão está subindo ou está alta.

Nos relatos há também referências a outros fatores que podem causar a elevação da pressão. Quatro entrevistados referiram-se à alimentação inadequada dando ênfase ao excesso de gordura e sal: "Pode ser alguma coisa que a gente come. Gordura, se eu comer demais me ofende, e o sal" (homem 1). A hereditariedade é citada por dois entrevistados. Um deles chegou a esta conclusão examinando seu próprio caso: "a gente ouve falar, agora a gente não sabe direitinho o porquê da pressão alta. (...) Se é, por exemplo, problema assim de alimentação, se é problema às vezes hereditário, né? Eu tenho problema de pressão. Minhas filhas também têm umas que tem problema de pressão" (mulher 20). Com menor freqüência, o cigarro, os problemas de coração e o calor também aparecem como causa da hipertensão. Foram cinco os entrevistados que disseram desconhecer o que pode causar a hipertensão/pressão alta: "Não sei, não tenho idéia não. (...) Não sei não, nem de ouvir falar" (mulher 3 ).

A maioria dos entrevistados acredita que a hipertensão/problema de pressão alta é grave porque pode ter conseqüências graves, como derrame, infarto e morte súbita, como ilustra o relato de um dos entrevistados: "é grave porque eu posso sofrer um derrame de uma hora para outra. Ou também posso sofrer um infarto também. Todos os dois são graves. Tem relação com pressão alta" (mulher 2). Cinco deles disseram ter sido informados por outras pessoas sobre a gravidade da pressão alta, mas pareciam não estar muito convencidos da veracidade desta informação, situação exemplificada pela fala de um dos entrevistados: “(...) eles falam que infarto e derrame dá é por causa de pressão alta. Elas falam, deve ser, né?" (mulher 3).

Dois entrevistados afirmaram que ter pressão alta só é um problema grave se o tratamento não estiver sendo feito. O relato de um dos entrevistados deixa isto bem claro: "Eu acho que sim, se não tratar pode até ser. Mas, a gente controlando bem com os remédios, acho que não é não. Eu penso que se a pessoa não tratar, por exemplo, se for assim numa altura assim de 20 e tantos pode ser perigoso, né? Pode ser, mais se for assim, mais ou menos normal, aí por uns 15 pra trás eu acho que não prejudica nada não" (homem 22). Um outro entrevistado mesmo tendo ouvido falar sobre a gravidade da pressão alta, disse que prefere não esquentar a cabeça: "Eles falam que é grave, eu não sei, mas eu não esquento muito a cabeça não porque se esquentasse eu acho que já tinha até morrido, sabe? (...) Assim, eu estou ruim, eu estou deitada e eu melhoro, eu estou de pé, andando" (mulher 14).

Dois entrevistados referiram-se à gravidade do problema de pressão mencionando a possibilidade de morte repentina quando a pressão sobe muito: "pressão é uma coisa de importância. Vê assim quantas pessoas que a pressão sobe e elas morrem de repente, né? Então tinha que cuidar da pressão" (mulher 13). 


\section{Ações}

De uma maneira geral, os entrevistados dizem que o fato de ter problema de pressão não traz grandes transtornos para suas vidas. Um deles relatou que não sente nada e que continua fazendo tudo: "Busco lenha, cada feixe pesado mesmo. Não sinto nada, graças a Deus" (mulher 18); um outro disse que nada mudou: "Não, $a$ mesma coisa de antes" (homem 22); e outro ainda explicou que o problema de pressão não acarretou mudança alguma: "Não, por conta da pressão, não (...). Não mudou nada" (mulher 8). Somente um entrevistado relatou ter tido a vida fortemente modificada após ter sofrido derrame.

Contudo, a maioria dos entrevistados referiu-se às dificuldades que surgem nos momentos em que a pressão sobe e manifesta-se por intermédio dos mais variados sintomas. Em muitos relatos, eles falaram que quando a pressão sobe são obrigados a mudar a rotina por não conseguirem realizar as tarefas habituais. Alguns disseram que ficam impossibilitados de fazer seu trabalho como de costume, seja em casa ou fora dela, e outros ainda relataram que quando a pressão está alta, não conseguem fazer nada a não ser ficar deitados. Para enfrentar esta situação, eles desenvolvem estratégias que visam minimizar o efeito da elevação da pressão em suas vidas. O repouso, por exemplo, foi citado por um dos entrevistados como um recurso utilizado quando a pressão sobe: "quando eu sinto alguma coisa eu fico mais de repouso. (...) Para mim isso não é doença, na minha cabeça não é doença, graças a Deus. É, estou falando de pressão, mas com as outras também é assim" (mulher 2). Um outro entrevistado explicou que quando percebe que a pressão está alta, ele diminui seu ritmo de vida: "o dia que eu sei que ela está alta eu manero a barra" (mulher 11).

Há também relatos de estratégias que têm mais especificamente o objetivo de tentar evitar a elevação da pressão. Alguns disseram passar a cuidar melhor da alimentação, como é o caso de um dos entrevistados que passou a se alimentar de carnes magras, usar um óleo de melhor qualidade para cozinhar e tirar sal da alimentação: "Tirei o sal, como com um óleo melhor. A comida não é magra mas também não é gorda. Eu como mais carne de frango. Se é uma carne de vaca, porco não entra aqui em casa, se é uma carne de vaca, procuro uma carne magra, mas mais é carne de frango que a gente come aqui em casa" (mulher 2). Outros procuraram tomar chás que acreditam ajudar a abaixar a pressão, como é o caso do entrevistado que passou fazer uso de chá de folha de chu- chu e chá de folha de abacate: "Tomo chá de folha de chuchu, tomo chá de folha de abacate. Parece que adianta, ajuda, né? É que eu vejo muita gente tomando e fala que abaixa. Alho, eles ensinam muito alho, às vezes eu como. Gosto de comer um dentinho de alho na hora da comida" (mulher 16). A caminhada é considerada por um outro entrevistado como um fator benéfico para o controle da pressão, por deixar a pessoa menos preocupada: "Eu faço caminhada todos os dias, gosto de fazer caminhada $e$ contemplar a natureza. (...) A caminhada também não é só para os gordinhos não, até pra mente, é bom para os nervos. A pessoa preocupada despreocupa um pouco. Então a pessoa menos preocupada pode né, uma coisa afeta a outra, a agulha puxa a linha" (homem 15).

Há ainda relatos de algumas estratégias que visam mais especificamente aliviar o peso dos problemas emocionais como procurar ficar mais tranqüilo, despreocupado ou diminuir o cigarro. Apesar de saber que cuidados com a alimentação são importantes, um entrevistado disse que a falta de dinheiro pode ser um empecilho: "Precisa cuidar, mas quando pode cuidar. Passou de 45 anos tem que alimentar muito bem, quando pode, né? Como é que eu vou comer muito bem se eu não tenho o cobre para comprar uma carne?" (mulher 13).

Vinte entrevistados afirmaram fazer o tratamento medicamentoso. Para ilustrar, segue a fala de um deles que disse cumprir rigorosamente a prescrição médica: "eu já saio da cama com o comprimido na mão. O que o médico manda eu faço, do jeito que ele manda eu faço. (...) Não pode parar não. Isso eu já fiquei certa, não vai parar não. Isso é porque a gente tem necessidade né? Para mim é importante o remédio. Eu sinto bem" (mulher 2).

Porém, quando analisados em profundidade, os relatos revelam uma situação um pouco diferente. Cinco daqueles que afirmaram fazer o tratamento relataram que modificam a dosagem prescrita: três aumentam e dois diminuem; três disseram que esporadicamente param de tomar o medicamento, e dois falaram que, às vezes, se esquecem de tomá-lo. Um entrevistado informou que contrariando a orientação médica de tomar o medicamento em dias alternados, prefere tomá-lo todos os dias porque tem medo que a pressão suba: "Tomo direto, $e u$ tomo de manhã, todo dia de manhã. O médico pediu para tomar um dia sim e outro não, mas eu tomo todo dia. Por acaso, sei lá se pode alterar o dia que eu falho, né?" (mulher 18). Um outro entrevistado disse que, por não estar sentindo nada, decidiu não tomar o medicamento duas vezes ao dia, conforme havia sido prescri- 
to pelo médico: "Tomo remédio, o médico mandou tomar um de manhã e um de noite. Agora eu só estou tomando um de noite porque eu não estou sentindo nada. Não precisa de eu tomar de manhã e de noite porque não sinto nada e não vou ficar tomando esta remediada não. (...) Eu só tomo remédio de noite porque eu não sinto nada não" (mulher 7). Outro, ainda explicou que sua pressão estava ficando muito baixa, e por esta razão decidiu diminuir a dose prescrita: "Eu nunca me automedico e sempre é a mesma dose, como o médico mandou, do jeito que ele mandou. (...) Eu falei com você que eu não mexo em nada, mas eu tomo há quarenta anos e agora eu estou partindo por conta própria. Porque ele inteiro era para abaixar e agora estou tomando essa dosagem para ver se a pressão sobe novamente, então eu dei uma partidinha" (mulher 12). Dentre aqueles que relatam de vez em quando parar de tomar o remédio, está um entrevistado que disse agir desta forma por acreditar que o problema já estava resolvido: "Eu achei que não tornava repetir, a dar. Eu achei que estava resolvido o problema" (mulher 5). Este mesmo entrevistado também disse que pára de tomar o medicamento por desconfiar da sua eficácia: "De vez em quando eu paro. Quando acaba às vezes eu falo 'acho que isso não tá valendo de nada'. E não tomava mesmo. (...) Não é por causa de dinheiro não, é porque vem na minha idéia que não estava valendo na$d a$ " (mulher 5). Esta questão da eficácia do medicamento também aparece no relato de outro entrevistado que esquece de tomá-lo de vez em quando: "quando às vezes a gente esquece de tomar o remédio, dá uma dor de cabeça, se às vezes a gente sente um mal estar, se é do nervoso ou se é da falta do remédio. A gente não sabe. Fico na dúvida se ele adianta, mas não deixo de tomar não" (mulher 26).

Após análise de todos os relatos, fica claro que dentre vinte entrevistados que inicialmente diziam estar fazendo o tratamento conforme prescrito, somente metade efetivamente o faz. Mesmo assim, entre estes dez que fazem o tratamento, um deles relata já ter interrompido o tratamento anteriormente, um acha que o medicamento está fraco, um afirma que o medicamento está lhe causando uma tosse e que já até recebeu conselho do irmão (que teve esta experiência com o mesmo remédio) para interromper seu uso, e um deles informa que passou a seguir corretamente a prescrição médica exclusivamente depois de um derrame. Dois outros afirmam fazer o tratamento, mas acreditam que ele não está adiantando, como é o caso do entrevistado que acha que seu organismo já acostumou com o remédio: "para mimo remédio não está adiantando não, às vezes, também eu já estou tomando esse remédio muito tempo, às vezes até eu já acostumei com ele porque remédio diz que a gente vai tomando muito tempo assim, um período prolongado, a gente parece que o organismo acostuma" (mulher 20).

Seis entrevistados informaram não fazer o tratamento, dentre eles, três explicaram que medicamentos para pressão nunca foram prescritos para eles, dois falaram que o empecilho maior é a falta de dinheiro para a aquisição do medicamento e um disse ter interrompido o tratamento porque já se achava melhor.

Em relação às consultas médicas, somente um entrevistado afirmou fazê-las regularmente: "eu consulto com convênio. (...) É de seis em seis meses, cinco meses" (homem 9). Cinco entrevistados tiveram sua última consulta médica há menos de oito meses, e sete há mais de dois anos. As justificativas para tal situação são as mais variadas. Um dos entrevistados afirmou que, como se sente bem, não vê necessidade de se consultar: "eu estou me sentindo bem, eu sou muito agraciada de Deus. Ele me dá essa força toda de cuidar da minha casa, essa alegria que eu tenho, então eu acho que não precisa, tô tomando o remédio" (mulher 2). Outro disse sentir-se desanimado pela ausência de condição financeira para pagar a consulta e pela ausência de condição física para enfrentar a marcação da mesma: "eu já acho que se eu não tenho o recurso, então eu não procuro. O caso é esse. Para mim não é muito fácil ir no médico. Para andar, para ficar assim no meio do povo, tudo para mim altera, aquilo me ataca. Não agüento ficar assim esperando. A pressão fica ruim, contrareio, ai ataca, ela altera" (homem 1).

As principais dificuldades de acesso à consulta médica relatadas referem-se à situação financeira, ao deslocamento e à disponibilidade de tempo para marcar a consulta. Segundo um entrevistado é difícil marcar a consulta porque sempre tem muita gente, o tempo gasto é muito grande e são constantes as mudanças de regras para a marcação das consultas: "Eles $m u$ dam muito. Tem época que é à noite que tem que ir para lá, outra época é à tarde, só para dar o nome da gente, no outro dia a gente tem que ir cedinho lá prá pegar a ficha. Consegue, com dificuldade consegue, mas não é fácil não" (mulher 8). Um outro entrevistado relatou dificuldade de locomoção e falta de dinheiro, o que inviabiliza a consulta: "a gente tem dificuldade porque não é todo dia que a gente tem dinheiro, está controlado não. Tem jeito não de compraro remédio e consultar, ainda eu quase não agüento andar, eu tenho que ir de condução e voltar" (mulher 21). 
Doze entrevistados relataram não ter dificuldades para se consultar. Destes, três explicaram que é fácil porque podem pagar a consulta. Os outros afirmaram que a posse de um plano de saúde privado ou Previdência, o fato de morar perto do serviço de saúde, ou de conhecer um funcionário deste serviço, facilitam o acesso às consultas. É interessante salientar que alguns dos entrevistados preferem pagar a consulta, quando podem, porque acham que o atendimento é melhor e a consulta é mais prolongada. Segundo um deles, quando paga a consulta se sente mais à vontade: "às vezes eu gosto de pagar a consulta. Eu acho que pagando a gente é melhor atendida. Tem diferença. A gente é mais bem examinada, o médico tem mais tempo. (...) Então eu não importo de pagar a consulta porque aí eu posso prolongar mais um pouco, me dá essa liberdade" (mulher 2).

Assim como no caso da consulta médica, o dinheiro também é importante na aquisição do medicamento. A maioria dos entrevistados relatou a necessidade de comprá-lo, fato que pode ser ilustrado pela fala de um deles quando explica que o medicamento distribuído gratuitamente é disputado por muita gente, às vezes falta e não é para todos: "o medicamento tem que comprar. No Postinho, às vezes, dão o remédio, mas é tanta gente (...). Não é para todo mundo também que eles dão. Eu compro, tem gente que tem problema, tem muita gente. (...) $E$ fica sem tomar. Tem o Posto que pode pegar, mas às vezes, na época não tem o remédio, pode faltar" (mulher 26). Na sua maioria, os relatos apontaram dificuldades em relação à aquisição do medicamento e também estratégias utilizadas pelos entrevistados para não interromper o tratamento. Um entrevistado explicou que, quando está sem dinheiro para comprar o remédio, apela para o crédito: “(...) se na hora a gente não tem dinheiro, a gente tem crédito e a gente compra, até o dia que o dinheiro chega" (mulher 20); outro narrou que para adquirir o remédio, às vezes, tem que deixar de comprar algum alimento: "o remédio, comprar a gente compra, com dificuldade mas compra. (...) Como é que faz? Tem hora que a gente tira de uma 'obra' de comer para poder comprar o remédio" (mulher 14). Dois entrevistados afirmaram não fazer o tratamento por falta de dinheiro para comprar o medicamento.

De uma maneira geral, as falas de dois entrevistados ilustram bem o que foi relatado pela maioria deles quanto ao tratamento da pressão alta. Um deles falou sobre a influência do dinheiro no tratamento da pressão: "com o tratamento melhora. (...) É fácil tratar principalmente tendo esse [dinheiro]. Quem não tem é mais custoso, dinheiro é importante em tudo. (...) Por exemplo, eu tenho a mesma doença, a senhora tem a mesma doença. Eu não tenho dinheiro ou por outra, a senhora não tem dinheiro. Rigorosamente eu passo na sua frente pelo meu dinheiro ou vice-versa. Dinheiro para pagar as consultas, pagar os remédios. O outro vai tratar com o tratamento grátis, gratuito" (homem 19). O outro complementou, explicando as estratégias utilizadas para lidar com as dificuldades encontradas no momento em que a pressão sobe: “(...) para ir no médico é difícil. (...) Aí eu dou um jeito em casa mesmo. Se eu vejo que a pressão tá alta, eu tomo remédio, tomo chá. É difícil também marcar a consulta. (...) Aqui não tem favorecimento nem de médico nem de um comprimido" (mulher 16).

A maior parte dos entrevistados concorda que pressão alta não tem cura. Segundo um deles, o fato de ter que tomar o remédio durante toda a vida é um indicativo que a pressão alta não tem cura: “(...) porque sempre que eu vou no médico ele fala que eu tenho que tomar esse remédio o resto da minha vida. Naturalmente não tem cura, né? Sou conformada, tudo bem" (mulher 3). Ainda que não tenha cura, a maioria dos entrevistados afirmou que o tratamento pode controlar a pressão; afirmação ilustrada pela fala do entrevistado quando explicou que o tratamento garante o controle: “(...) O tratamento vai levando e a idade vai passando. O remédio garante que a pressão não sobe" (mulher 11). Um outro também afirmou que se o tratamento for feito corretamente, a pressão fica controlada: “(...) se o sujeito for medicado certinho ele entra na linha. É igual um carro andando na linha. Se ele tiver na marcha de competência da lei, ele vai. Se ele não tiver, ele não vai" (homem 9). Apenas três entrevistados afirmaram que a pressão alta tem cura.

\section{Discussão}

\section{Sistemas de Signos, Significados e Ações} associados à hipertensão arterial

Com relação ao conhecimento do diagnóstico, dois dos entrevistados afirmaram não ser hipertensos/ter problema de pressão. Isto é no mínimo intrigante porque mesmo que eles nunca tenham recebido esta informação por um médico, já que estavam participando do Projeto Bambuí, devem ter sido informados de seu diagnóstico. Durante a realização do Projeto Bambuí, quando um participante era considerado hipertenso, além de ser explicado a ele que a sua pressão estava alta e que deveria pro- 
curar um médico para fazer um acompanhamento, ele também recebia um formulário contendo os valores das medidas de sua pressão arterial e uma instrução para que ele procurasse um médico. Nesta ocasião, um acordo entre a coordenação do Projeto Bambuí e a Prefeitura Municipal de Bambuí garantiu, por meio do Sistema Único de Saúde, atendimento médico a todos os participantes encaminhados pela equipe do Projeto.

O desconhecimento do diagnóstico pode estar relacionado à não-compreensão da informação ou à negação da condição de hipertenso. Estas situações podem estar refletindo dificuldades de comunicação entre médico e paciente ou simplesmente a incapacidade do entrevistado de considerar-se doente. É importante ressaltar que o não-reconhecimento do diagnóstico pode ter grande repercussão na adesão aos programas e tratamentos relativos à hipertensão. Quem não é doente não precisa de se tratar.

De uma maneira geral, os entrevistados associaram explicitamente o aparecimento de alguns problemas como tonteira, mal-estar, dor de cabeça, ao aumento da pressão etc. Estes problemas também foram mencionados em dois outros estudos, um com idosos pacientes de uma clínica em Araraquara 23, e outro realizado com americanos residentes em área urbana 40 . No presente estudo, a presença destes problemas foi percebida como um sinal de alerta que informa que a pressão está alta ou está subindo e que é necessário fazer alguma coisa para controlá-la. Neste momento, a maioria dos entrevistados procura um médico, toma corretamente o medicamento ou ainda desenvolve estratégias para evitar conseqüências graves. É importante ressaltar que a eleição de um sinal de alerta tem algumas repercussões importantes, isto é, somente quando ele está presente é preciso preocupar-se com o problema de pressão ou fazer alguma coisa para resolvê-lo.

Outro fato que chama a atenção é o número significativo de entrevistados que identifica a família (problemas familiares) como a fonte de "problemas emocionais", que por sua vez são considerados os principais responsáveis pelo aumento da pressão. Os problemas familiares também aparecem nos estudos de Carvalho et al. 23, Heurtin-Roberts 41, Greenfield et al. 42 e Blumhagen 40 , como possíveis causadores da hipertensão. No nosso estudo, a ocorrência de problemas familiares é entendida como indício de que a pressão poderá subir. Neste momento, acredita-se que é preciso ficar mais vigilante em relação à pressão ou mesmo tomar alguma atitude a fim de controlá-la. Ca- so contrário, se tudo vai bem com a família acredita-se que dificilmente a pressão subirá. Tal situação merece atenção, uma vez que, estabelecida esta relação, os comportamentos dos entrevistados em relação ao controle da pressão serão, em grande parte, dependentes da identificação de problemas familiares. Um outro estudo conduzido nesta mesma comunidade ressaltou a família como a primeira fonte de suporte em todas as áreas, desempenhando um papel fundamental nos momentos de doença 11. Isso poderia explicar por que qualquer problema com a família constitui um acontecimento tão ameaçador.

Entre os entrevistados existe quase um consenso de que a hipertensão/pressão alta é grave porque ela pode ter conseqüências desastrosas (derrame, infarto e morte súbita). Todavia, chama a atenção a difusão entre eles da idéia de que a hipertensão/pressão alta não traz maiores repercussões para a vida cotidiana. O que é visto como problemático são os momentos em que a pressão sobe e manifesta-se por intermédio de sintomas que alteram a rotina destes indivíduos. Essa situação determina o desenvolvimento de algumas estratégias que visam evitar que a pressão suba ou controlar a pressão quando ela está alta.

De uma maneira geral, os entrevistados concordam que o tratamento é necessário porque, embora não cure, controla a pressão. Entretanto, um fato no mínimo curioso é que, apesar da maioria informar que faz o tratamento, seus relatos deixam claro que grande parte deles não segue a prescrição médica corretamente. Isso nos leva a interrogar sobre qual é a concepção que eles têm do que é seguir corretamente um tratamento. O conjunto de relatos deixa claro que a ausência de sintomas permanentes faz com que muitos entrevistados não se sintam doentes e assim subestimem a importância de fazer tratamento continuado conforme a prescrição médica. Ao contrário, quando eles têm alguns sintomas específicos, acreditam que a pressão está alta e que nestes momentos o tratamento é indispensável.

$O$ presente estudo também deixa claro que a falta de dinheiro pode dificultar o acesso à consulta médica e a aquisição do medicamento. $\mathrm{O}$ alto custo dos medicamentos também foi identificado pelos idosos de Araraquara 23 como um obstáculo para manter a regularidade do tratamento. No nosso estudo, o problema de deslocamento e o tempo dispensado para marcar consultas foram outras dificuldades destacadas pelos entrevistados. Para contornar estas dificuldades são freqüentemente desenvolvidas estratégias (comprar o medicamento 
a crédito, deixar de comprar alimentos para comprar o medicamento, tomar chás que acreditam ser bons para a pressão, apelar para um conhecido que trabalhe no serviço de saúde para facilitar a marcação de uma consulta médica) que podem intervir de forma importante na continuidade ou no início do tratamento.

$\mathrm{O}$ retorno à distinção entre disease e illness, estabelecida por Eisenberg 27, facilitará um melhor entendimento das "maneiras de pensar e agir" dos idosos de Bambuí. O conjunto de narrativas analisado veicula um discurso aparentemente semelhante ao discurso biomédico (disease). No entanto, uma análise aprofundada das narrativas deixa claro que os termos e conceitos médicos utilizados são geralmente reapropriados e reinterpretados pelos entrevistados, que lhes atribuem significado muitas vezes diferente do que lhes confere a biomedicina. Podemos dizer que os idosos de Bambuí possuem uma concepção particular do que é problema de pressão, quais são suas causas, qual é a gravidade deste problema, quais são as manifestações importantes e qual é a importância de tratar-se (illness). O eixo organizador das narrativas é uma clara distinção entre "problema de pressão" e "pressão alta”. "Problema de pressão" é considerado como um estado permanente que não traz grandes problemas para o dia a dia e que tem como característica principal a ausência de sintomas e de fatores emocionais que podem desencadear a "pressão alta". "Pressão alta”, por sua vez, é considerada como um estado abrupto que é grave.
Acredita-se que este estado é geralmente desencadeado por problemas familiares e pode ser facilmente reconhecido pela identificação de algumas manifestações específicas. Parece que, para os idosos de Bambuí, o que constitui um problema não é ter o diagnóstico de hipertensão/problema de pressão, mas sim saber que a pressão está alta ou subindo. Para eles, o tratamento é visto como necessário somente nos momentos em que a pressão sobe. Cabe ressaltar que, mesmo nesses casos, questões financeiras podem dificultar o acesso às consultas médicas ou à compra do medicamento, vindo assim impedir o início ou a continuidade do tratamento. Dessa forma, a importância de buscar tratamento ou seguir corretamente a prescrição médica fica dependente da identificação do aumento da pressão, seja pela presença de sintomas específicos, seja pela presença de condições favoráveis à elevação da pressão.

A análise do sistema de Signos, Significados $e$ Ações associados à hipertensão permitiu delimitar uma rede de significados que articula idéias sobre manifestações, repercussões e tratamento e vem configurar uma concepção específica da hipertensão. Tal concepção, assim como os fatores contextuais (recursos financeiros, acesso a serviços e medicamentos etc.), que influenciam a construção de comportamentos concretos, devem ser levados em conta na elaboração de campanhas educativas e programas relativos à hipertensão.

\section{Resumo}

As maneiras de pensar e de agir de idosos frente à hipertensão arterial foram investigadas, utilizando-se uma abordagem antropológica baseada no modelo de Signos, Significados e Ações 1. Participaram do trabalho 26 idosos ( $\geq 60$ anos), selecionados aleatoriamente entre hipertensos participantes da linha de base da coorte de Bambuí. O eixo organizador das narrativas mostrou uma clara distinção entre "problema de pressão" e "pressão alta". A "pressão alta" é desencadeada especialmente por problemas familiares e pode ser facilmente reconhecida pela identificação de algumas manifestações específicas; o que é considerado problemático é o momento em que a pressão sobe, único momento em que as intervenções são vistas como neces sárias. Desta forma, a importância de buscar o tratamento ou seguir corretamente a prescrição médica fica dependente da identificação de um aumento da pressão, seja pela presença de sintomas específicos, seja pela presença de condições subjetivas favoráveis à elevação da pressão arterial. Dificuldades financeiras para a obtenção da consulta médica e para a aquisição dos medicamentos são também identificadas pelos idosos como fatores que dificultam o início ou a continuidade do tratamento da hipertensão arterial.

Idoso; Hipertensão; Antropologia 


\section{Colaboradores}

J. O. A. Firmo foi responsável pela coleta e análise dos dados e redação do trabalho. M. F. Lima-Costa participou na discussão do desenho do estudo, resultados e revisão crítica final do artigo. E. Uchôa contribuiu no delineamento do estudo, supervisão da análise dos dados e da redação do trabalho.

\section{Referências}

1. Corin E, Uchôa E, Bibeau G, Koumaré B, Coulibaly B, Coulibaly M, et al. La place de la culture dans la psychiatrie africaine d'aujourd'hui. Parametres pour un cadre de références. Psychopathologie Africaine 1992; 24:149-81.

2. United Nations. World population projections to 2125. Popul Dev Rev 1998; 24:183-9.

3. Caldwell JC. Population health in transition. Bull World Health Organ 2001; 79:159-60.

4. Lima-Costa MF, Guerra HL, Barreto SM, Guimarães RM. Diagnóstico da situação de saúde da população idosa brasileira: um estudo da mortalidade e das internações hospitalares públicas. Inf Epidemiol SUS 2000; 9:23-41.

5. Omran AR. The epidemiologic transition: a theory of the epidemiology of population change. Milbank Mem Fund Q 1971; 49:509-38.

6. National Hight Blood Pressure Education Program Working Group. National high blood pressure education program working group report on hypertension in the elderly. Hypertension 1994; 23:275-85.

7. Lessa I. Epidemiologia da hipertensão arterial. In: Lessa I, organizador. O adulto brasileiro e as doenças da modernidade. Epidemiologia das doenças crônicas transmissíveis. São Paulo: Editora Hucitec/Rio de Janeiro: ABRASCO; 1998. p. 77-96.

8. Kannel WB. Cardioprotection and antihypertensive therapy: the key importance of addressing the associated coronary risk factors (the Framingham experience). Am J Cardiol 1996; 77:6B-11B.

9. Whelton PK. Epidemiology of hypertension. Lancet 1994; 344:101-6.

10. Marques-Vidal P, Tuomilehto J. Hypertension awareness, treatment and control in the community: is the "rule of halves" still valid? J Hum Hypertens 1997; 1:213-20.

11. Uchôa E, Firmo JOA, Lima-Costa MFF. Envelhecimento e saúde: experiência e construção cultural. In: Minayo MCS, Coimbra Jr. CEA, organizadores. Antropologia, saúde e envelhecimento. Rio de Janeiro: Editora Fiocruz; 2002. p. 25-35.

12. Firmo JOA, Barreto SM, Lima-Costa MF. The Bambuí Health and Aging Study (BHAS): factors associated with the treatment of hypertension in older adults in the community. Cad Saúde Pública $2003 ; 19: 817-27$.

13. Firmo JOA, Uchôa E, Lima-Costa MF. Projeto Bambuí: fatores associados ao conhecimento da condição de hipertenso entre idosos. Cad Saúde Pública 2004; 20:512-21.
14. Barreto SM, Passos VMA, Firmo JOA, Guerra HL, Vidigal PG, Lima-Costa MFF. Hypertension and clustering of cardiovascular risk factors in a community in Southeast Brazil - The Bambuí Health and Ageing Study. Arq Bras Cardiol 2001; 77: 576-81.

15. Trindade IS, Heineck G, Machado JR, Ayzemberg H, Formighieri M, Crestane M. Prevalência da hipertensão arterial sistêmica na população urbana de Passo Fundo (RS). Arq Bras Cardiol 1998; 71:127-30.

16. Piccini RX, Victora CG. Hipertensão arterial sistêmica em área urbana no sul do Brasil: prevalência e fatores de risco. Rev Saúde Pública 1994; 28:261-7.

17. Carneiro O, Jardim PCBV. Pressão arterial em tribos Xavantes. Comparação 15 anos depois. Arq Bras Cardiol 1993; 61:279-82.

18. Lólio CA. Prevalência da hipertensão arterial em Araraquara. Arq Bras Cardiol 1990; 55:167-73.

19. Klein CH. Hipertensão arterial em estratos geoeconômicos do Rio Grande do Sul [Dissertação de Mestrado]. Rio de Janeiro: Escola Nacional de Saúde Pública, Fundação Oswaldo Cruz; 1981.

20. Klein CH, Araújo JWG, Leal MC. Inquérito epidemiológico sobre a hipertensão arterial em Volta Redonda, Rio de Janeiro. Cad Saúde Pública $1985 ; 1: 58-70$.

21. Barreto ML, Meira RCL. Hipertensão arterial sistêmica em uma comunidade do oeste do Estado da Bahia (Brasil). Arq Bras Cardiol 1980; 34:363-6.

22. Dressler W, Santos JE. Social and cultural dimensions of hypertension in Brazil: a review. Cad Saúde Pública 2000; 16:303-15.

23. Carvalho F, Telarolli Jr. R, Machado JCMS. Uma investigação antropológica na terceira idade: concepções sobre a hipertensão arterial. Cad Saúde Pública 1998; 14:617-21.

24. Fuchs FD, Moreira LB, Moraes RS, Bredemeier M, Cardozo SC. Prevalência da hipertensão arterial sistêmica e fatores associados na região urbana de Porto Alegre. Estudo com base populacional. Arq Bras Cardiol 1994; 63:473-9.

25. Ayres JEM. Prevalência da hipertensão arterial na Cidade de Piracicaba. Arq Bras Cardiol 1991; 71:33-6.

26. Geertz C. The interpretation of cultures. New York: Basic Books; 1973.

27. Eisenberg L. Disease and illness: distinctions between professional and popular ideas of sickness. Cul Med Psychiatry 1977; 1:9-23.

28. Kleinman A. Patients and healers in the context 
of cultures. An exploration of boderland between Antropology and Psychiatry. Berkeley/Los Angeles: University of California Press; 1980.

29. Good BJ. The heart of what's the matter: the semanties of illness in Iran. Cult Med Psychiatry 1977; 1:25-58.

30. Good B, Del Vecchio, Good MJ. The meaning of symptoms: a cultural hermeneuric model for clinical practice. In: Eisenberg L, Kleinman A, editors. The relevance of social science for medicine. Dordrecht: D. Reidel Publishing; 1980. p. 165-96.

31. Good B, Del Vecchio MJ. Toward a meaning-centered analysis as popular illness categories: "fright-illness" and "heart distress" in Iran. In: Marsella AJ, White GM, editors. Cultural conceptions of mental health and therapy. Dordrecht: D. Reidel Publishing; 1982. p. 141-66.

32. Uchôa E. Epidemiologia e antropologia. Contribuições para uma abordagem dos aspectos transculturais da depressão. In: Canesqui AM, organizador. Ciências sociais e saúde. São Paulo: Editora Hucitec/Rio de Janeiro: ABRASCO; 1997. p. 87-109.

33. Kleinman A, Good B. Culture and depression studies in anthropology and cross-cultural psychiatry of affect and disorder. Berkeley: University of California Press; 1985.

34. Uchôa E, Vidal JM. Antropologia médica: elementos conceituais e metodológicos para uma abordagem da saúde e da doença. Cad Saúde Pública 1994; 10:497-504.
35. Corin E, Uchôa E, Bibeau G, Harnois G. Les attitudes dans le champ de la santé mentale. Repères théoriques et méthodologiques pour une étude ethnographique et comparative. Montréal: Centre de Recherche de l'Hôpital Douglas, Centre Collaborateur OMS; 1989. (Rapport Technique).

36. Corin E, Bibeau G, Martin JC, Laplante R. Comprendre pour soigner autrement. Rep'eres pour régionaliser les services de santé mentale. Montréal: Presses de l'Université de Montréal; 1990.

37. Corin E, Uchôa E, Bibeau G, Koumare B. Articulation et variations des systèmes de signes, de sens et d'actions. Psychopathologie Africaine 1992; 24:183-204.

38. Corin E, Bibeau G, Uchôa E. Eléments d'une semiologie anthropologique des troubles psychiques chez les Bambara, Bwa et Soninké du Mali. Anthropol Soc 1993; 17:125-56.

39. Lima-Costa MF, Uchôa E, Guerra HL, Firmo JOA Vidigal PG, Barreto SM. The Bambuí Health and Ageing Study (BHAS): methodological approach and preliminary results of a population-based cohort study of the elderly in Brazil. Rev Saúde Pública 2000; 34:126-35.

40. Blumhagen D. Hyper-tension: a folk illness with a medical name. Cult Med Psychiatry 1980; 4:197224.

41. Heurtin-Roberts S. "High-Pertension" - the uses of a chronic folk illness for personal adaptation. Soc Sci Med 1993; 37:285-94.

42. Greenfield SF, Borkan J, YodfatY. Health beliefs and hypertension: a case-control study a Moroccan Jewish Community in Israel. Cult Med Psychiatry 1987; 11:79-95.

Apresentado em 01/Ago/2003

Versão final reapresentada em 05/Mar/2004

Aprovado em 23/Mar/2004 